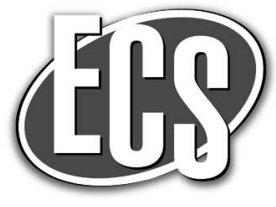

\title{
Equivalent Circuits and Efficacy of Single-Layer ACPEL Devices
}

\author{
C. J. Winscom, ${ }^{\mathrm{Z}}$ P. G. Harris, and J. Silver
}

Centre for Phosphors and Display Materials, Wolfson Centre for Materials Processing, Brunel University, Uxbridge, Middlesex UB8 3PH, United Kingdom

\begin{abstract}
A series resistance - capacitance equivalent circuit has been used to describe a single layer AC Powder Electroluminescence (ACPEL) lamp in operation. The two crucial components of this practical equivalent circuit are frequency and voltage dependent and have been independently determined for a single layer ACPEL device over a range of $50-800 \mathrm{~Hz}$ and $10-150 \mathrm{~V}$. The organic binder containing a ferroelectric component is mainly responsible for determining the capacitive element since it acts in series with a larger capacitative contribution mainly from the phosphor. The series resistive element will be determined by mainly the phosphor particles, and the remarkable changes in the effective series resistance and capacitance of the lamp structure are shown to be brought about by the activation of the $\mathrm{ZnS}$ phosphor. The effective resistance is consistent with a model where conductivity is governed by the average charge recombination time under given internal field and frequency conditions. Using the effective resistance and capacitance values of our equivalent circuit, the average rate of energy dissipation can be easily calculated as a function of applied voltage and frequency. For sinusoidal waveforms, first indications are that efficacy will be optimized at low voltages, but only weakly dependent on frequency.

(C) The Author(s) 2014. Published by ECS. This is an open access article distributed under the terms of the Creative Commons Attribution Non-Commercial No Derivatives 4.0 License (CC BY-NC-ND, http://creativecommons.org/licenses/by-nc-nd/4.0/), which permits non-commercial reuse, distribution, and reproduction in any medium, provided the original work is not changed in any way and is properly cited. For permission for commercial reuse, please email: oa @ electrochem.org. [DOI: 10.1149/2.015406jss] All rights reserved.
\end{abstract}

Manuscript submitted March 14, 2014; revised manuscript received April 28, 2014. Published May 8, 2014.

Thick film AC electroluminescence, also referred to as AC powder electroluminescence (ACPEL), can be achieved with a simplyconstructed layer structure to produce a surface-distributed light source. The first examples were reported by Destriau in $1936 .{ }^{1} \mathrm{Al}$ though the main characteristics of ACPEL were well-documented in early studies, ${ }^{2-5}$ the absence of a proven mechanism at the time meant that a detailed understanding was lacking. Today, the generally accepted mechanism for ACPEL was one first advanced by Fischer in $1965 .^{6}$ In typical $\mathrm{ZnS}: \mathrm{Cu}, \mathrm{Cl}$ phosphor materials, this mechanism relies on the existence of discrete sub-micron $\mathrm{Cu}_{\mathrm{x}} \mathrm{S}$ domains, variously described as "needles" or "precipitates" within the $\mathrm{ZnS}$ structure. ${ }^{7-12}$

More modern surface-distributed electroluminescent technologies, e.g. white light OLED technologies, are current-driven and efficacies of 28 lumen/W for smOLED's ${ }^{13}$ and 18 lumen/W for pOLED's ${ }^{14}$ have been recently cited. Each of these may be doubled with additional but more costly - out-coupling technology. By comparison, white light ACPEL lamps are field-driven, and are generally regarded to achieve only the order of $1-3$ lumen/W. ${ }^{15,16}$ More recently, however, much higher efficacies have been claimed. ${ }^{17}$ The two unassailable advantages of ACPEL lighting are (1) the economy of manufacture, particularly as a device with a single active layer, and (2) the functional flexibility of large areas. Improving the efficacy of this light source is therefore a worthy challenge.

ACPEL devices are generally assumed to have essentially capacitative characteristics, borne out by direct resistance and capacitance measurements of a device under zero field conditions. Applying a sinusoidal AC voltage under working conditions should render the voltage and current drawn to be 90 degrees out of phase with each other, with concomitantly efficient power consumption. This observation prompts the question: why is the measured efficacy of ACPEL devices so low? A number of preliminary observations concerning different lamp architectures under a variety of current, voltage, frequency and waveform conditions pointed to characteristics in contradiction to the assumption above in the sense that the electronic characteristics of ACPEL lamps were changing as a function of applied voltage and frequency.

In this work we shall show that these characteristics change, and deduce the underlying causes for these changes. The results lay the groundwork for designing a high efficacy ACPEL architecture, an example of which will be presented in a forthcoming report.

\section{Experimental}

Device architectures. - Various different device architectures are commonly in use; we have chosen a forward architecture as shown in Figure 1. The use of sputtered indium tin oxide (ITO) on a PET base mean that the lamps are brighter than reverse architectures which usually employ PEDOT/PSS with a lower transmission and conductivity, as the transparent electrode.

Materials. - Forward architecture single layer ACPEL panels were prepared as previously described ${ }^{18}$ by screen-printing a phosphor (GTP Sylvanier GG25) in a binder (ethyl cellulose SigmaAldrich) containing an additional ferroelectric (barium titanate, Sigma-Aldrich) onto an ITO-coated polyethylene terephthalate (PET) substrate (supplied by Visiontek Ltd., UK), and then printing a backing electrode using silver ink (AG500 supplied by Nicomatic, UK). They corresponded to the construction in Figure 1 with the optional dielectric layer omitted. In a typical working single-layer ACPEL the proportions of phosphor $(\mathrm{P})$ :ferroelectric $(\mathrm{FE})$ :binder(B) are $3: 1: 4 \mathrm{vol} / \mathrm{vol}$.

To monitor changes in electrical characteristics, panels were produced in which either the activated phosphor was replaced by an equivalent non-activated material (zinc sulfide, laboratory reagent grade, $\mathrm{BDH})$, or the activated phosphor or ferroelectric components were

\section{Luminescence}

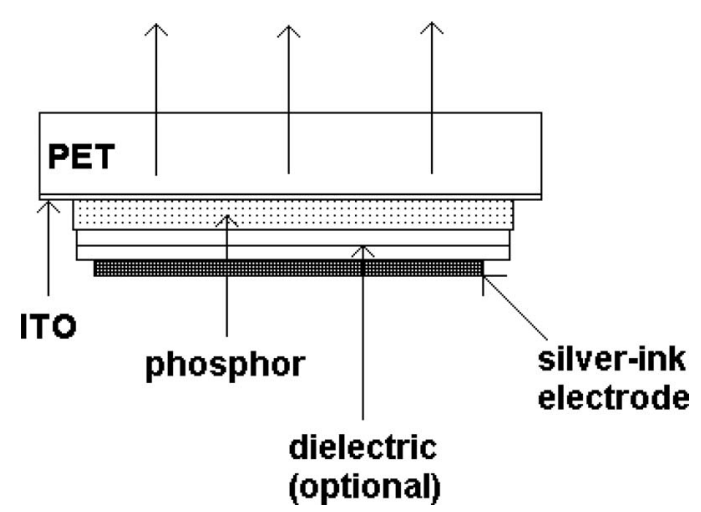




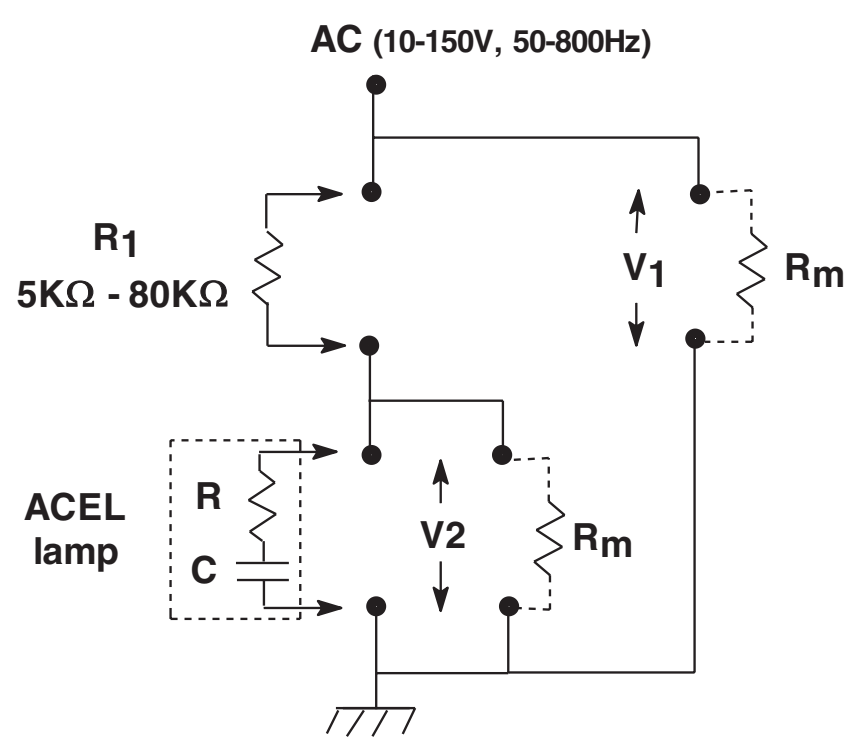

Figure 2. Circuit arrangement for measuring $\left(\mathrm{V}_{2} / \mathrm{V}_{1}\right)$ and the phase of $\mathrm{V}_{2} \mathrm{vs}$. $\mathrm{V}_{1}$. The input impedances $\left(\mathrm{R}_{\mathrm{m}}\right)$ are matched, and are taken into account in the analysis when the $\mathrm{R}$ and $\mathrm{C}$ of Figure 3 are determined.

omitted entirely. The active area of all devices was in the range 30 to $50 \mathrm{~cm}^{2}$. The surface resistivity of silver ink electrodes is typically $<1 \Omega$ /square; indium tin oxide coatings are typically 40 $120 \Omega$ /square. In the single layer architecture of our devices using either an activated- or nonactivated $\mathrm{ZnS}$ layer, the non-operational characteristics are typically a capacitance of $15-30 \mathrm{nF}$ and an unmeasurable (>40 M $\Omega$ ) DC resistance.

Measurements. - Sinusoidal AC voltages up to $\pm 10 \mathrm{~V}$ were provided by a general purpose signal generator (Quantec PSM2200, Newtons4th Ltd.). It also incorporated two isolated voltage measurement channels for measuring true rms voltages, or acting together as a vector voltmeter. The input impedances were both $1 \mathrm{M} \Omega$. An amplifier (Newtons 4th Ltd.) was used to deliver up to $\pm 150 \mathrm{~V}$ in the range 50-800 Hz. The arrangement for monitoring $\mathrm{V}_{2} / \mathrm{V}_{1}$ and the phase of $\mathrm{V}_{2}$ vs. $\mathrm{V}_{1}$ was that shown in Figure 2.

The input impedance $\left(\mathrm{R}_{\mathrm{m}}\right)$ of the voltage measurement and phase comparison channels play a role and must be accounted for in the expressions used to determine the effective $\mathrm{R}$ and $\mathrm{C}$ values of the lamp. The series resistance $\left(\mathrm{R}_{1}\right)$ in Figure 2 was set at $80 \mathrm{~K} \Omega, 40 \mathrm{~K} \Omega, 20 \mathrm{~K} \Omega$, $10 \mathrm{~K} \Omega$ and $5 \mathrm{~K} \Omega$ for the frequencies $50 \mathrm{~Hz}, 100 \mathrm{~Hz}, 200 \mathrm{~Hz}, 400 \mathrm{~Hz}$ and $800 \mathrm{~Hz}$, respectively. $\mathrm{R}$ - and $\mathrm{C}$-values were then determined according to the expressions derived in the next section. Finally, the derived R- and C-values at voltage amplitudes $10-150 \mathrm{~V}$ were confirmed using the bridge circuit in Figure 3.

\section{Theory}

MacDonald ${ }^{19}$ considered the situation of a uniform distribution of centers undergoing charge separation in a slab of material placed between two blocking electrodes. His equivalent circuit represented the high- and low frequency limits using two ohmic conductive elements and three capacitative elements. The single layer ACPEL contains a particulate phosphor and a much smaller particulate ferroelectric embedded in an organic binder, and placed between two conductive electrodes. The number of independent conductive and capacitative elements to represent this situation becomes unwieldy, and we seek a pragmatic simplification which may be examined experimentally and subsequently used for efficacy optimisation. The equivalent circuit shown on the left in Figure 4 is based on that proposed originally by MacDonald. ${ }^{19} R_{P}$ and $C_{P}$ are the resistive and capacitative contributions mainly from the phosphor with some contribution from both the

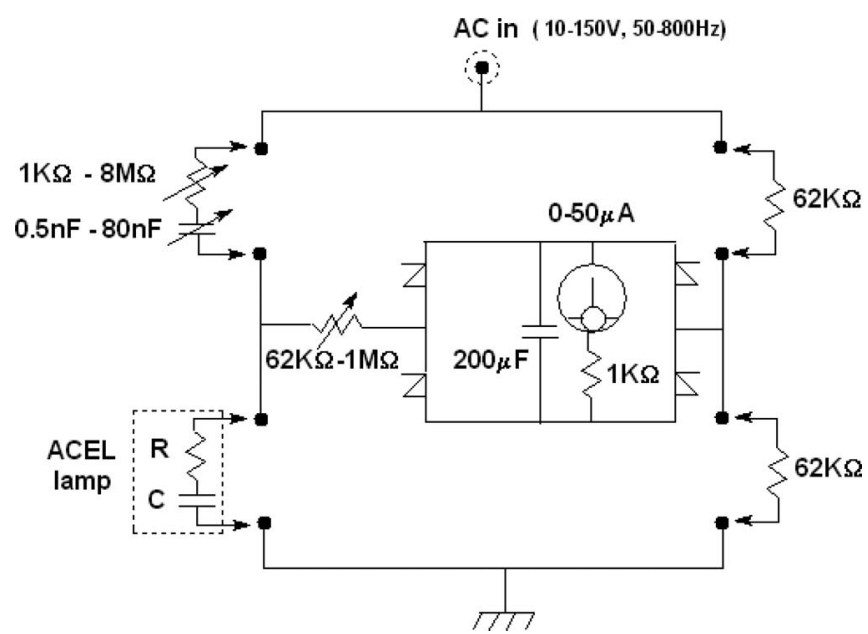

Figure 3. Bridge circuit used to confirm series R-C characteristics determined by the procedure described with the help of Figure 2.

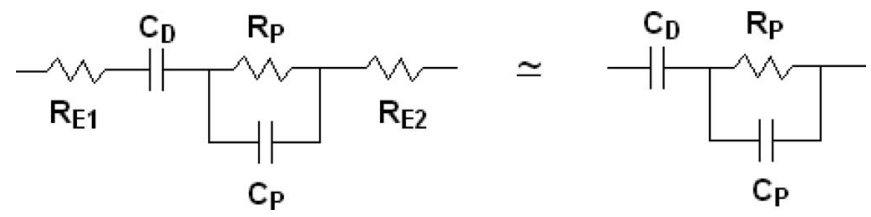

Figure 4. The simplified equivalent circuit of an ACPEL lamp. The electrode resistances can be considered negligible.

ferroelectric and the binder, whilst $\mathrm{C}_{\mathrm{D}}$ is a capacitative contribution mainly from the dielectric binder blocking direct ohmic conductivity to the particulate components, and $\mathrm{R}_{\mathrm{E} 1}, \mathrm{R}_{\mathrm{E} 2}$ the resistive contributions from the two electrodes. Broadly speaking, when silver and ITO are the electrode materials $R_{\mathrm{E} 1}, R_{\mathrm{E} 2} \ll R_{\mathrm{P}}$, which lies in the range 1-1000 $\mathrm{K} \Omega$. The important elements of the circuit can be reduced to those shown on the right in Figure 1, and is one of several analyzed by Enikeeva. ${ }^{20}$

In an ACPEL lamp, the activated phosphor particles will be semiconducting, so that it is anticipated that $R_{P}$ and $C_{P}$ will depend on the amplitude and frequency of the applied external field. One problem is that an approach to determine $C_{D}, C_{P}$ and $R_{P}$ independently as functions of voltage and frequency is thwarted, since in electrical terms the only two experimentally accessible quantities are the voltage drop across the device, as load in a potential chain, and the current-voltage phase difference in the device. A second problem is that the use of modern binder materials, such as coatable polymers incorporating additional ferroelectric components like $\mathrm{TiO}_{2}$ and $\mathrm{BaTiO}_{3}$, inevitably contain a small proportion of moisture.

This suggests that some ionic conductivity could be present, represented as a resistive leakage, $\mathrm{R}_{\mathrm{L}}$, in the circuit on the left in Figure 5. In addition, it is also possible that there is some statistical "touching"

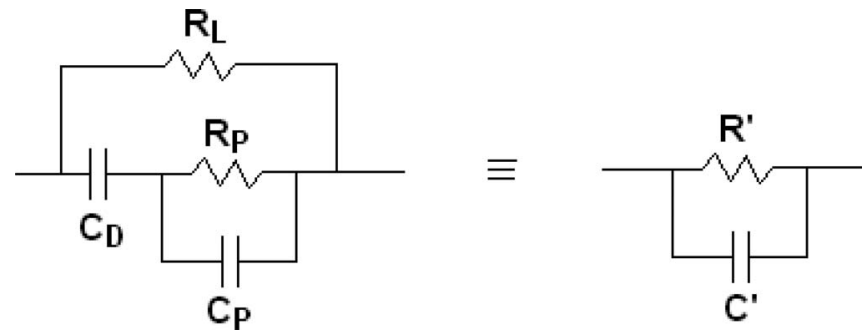

Figure 5. The equivalent circuit if residual conductivity is present. It can be represented in terms of parallel effective resistive- and capacitative components shown on the right (see text). 


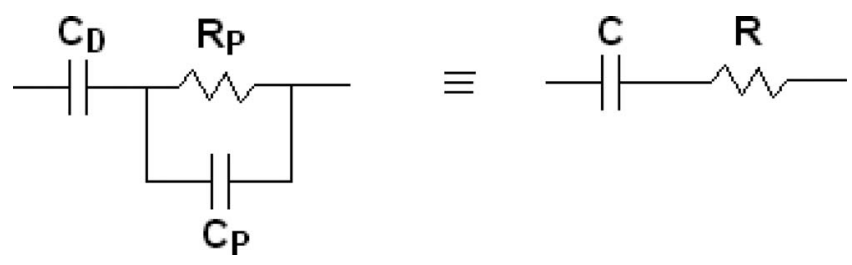

Figure 6. The most appropriate equivalent circuit (left) and its reduced form as effective $\mathrm{R}$ - and $\mathrm{C}$-components in a series configuration.

of the phosphor particles at the electrodes that can facilitate this effect. In this case, the equivalent circuit on the left in Figure 5 can be reduced to the parallel arrangement on the right comprising an effective resistance $\left(\mathrm{R}^{\prime}\right)$ and capacitance $\left(\mathrm{C}^{\prime}\right)$ pair that can be independently determined. Though complex, $\mathrm{R}^{\prime}$ and $\mathrm{C}^{\prime}$ can be expressed as functions of $C_{D}, C_{P}, R_{P}, R_{L}$ and frequency for further analysis. However, in a recent report ${ }^{21}$ this was shown to be insignificant $\left(\mathrm{R}_{\mathrm{L}}>8 \mathrm{M} \Omega\right)$ at the typical operating voltages of the single layer lamps we have fabricated. Therefore, we conclude that the equivalent circuit on the left in Figure 6 is that most appropriate.

In this case the three elements $C_{D}, C_{P}$ and $R_{P}$ can again be reduced to an effective resistance $(\mathrm{R})$ and capacitance $(\mathrm{C})$ pair but now in a series configuration. The reasonably compact expressions for $\mathrm{R}, \mathrm{C}$ become:

$$
\begin{gathered}
\mathrm{R}=\mathrm{R}_{\mathrm{P}} /\left(1+\mathrm{W}_{\mathrm{P}}^{2}\right) \\
1 / \mathrm{C}=\left(1 / \mathrm{C}_{\mathrm{D}}\right)+\left(1 / \mathrm{C}_{\mathrm{P}}\right) \cdot\left\{\mathrm{W}_{\mathrm{P}}^{2} /\left(1+\mathrm{W}_{\mathrm{P}}^{2}\right)\right\}
\end{gathered}
$$

where $W_{P}=\omega C_{P} R_{P}$ and $\omega$ is the angular frequency in radians $s^{-1}$. $\mathrm{R}$ and $\mathrm{C}$ are determined experimentally as independent quantities, and their dependence on voltage and frequency can be examined. It is worth noting that if the relationship between $C_{P}$ and $C_{D}$ can be obtained by other means, then all three quantities can be determined. Finally, if a sinusoidal voltage of $\mathrm{V}_{0} \cos \omega \mathrm{t}$ at time $\mathrm{t} \mathrm{s}$. is applied to the series arrangement in Figure 6 to produce a current $I_{0} \cos (\omega t$ $+\Phi)$, the average rate of energy dissipation in the lamp, E (Joules $\mathrm{s}^{-1}$ ), by integration over one cycle is given by:

$$
\mathrm{E}=1 / 2 \cdot \mathrm{V}_{0} \mathrm{I}_{0} \cos \Phi=1 / 2 \cdot\left(\mathrm{V}_{0}^{2} / \mathrm{R}\right) \cdot \mathrm{W}^{2} /\left(1+\mathrm{W}^{2}\right)
$$

where $\Phi$ is the current-voltage phase difference and $\mathrm{W}=\omega \mathrm{CR}$ using the effective series resistance $\mathrm{R}$ and capacitance $\mathrm{C}$.

Referring now to Figure 2, $\mathrm{R}$ and $\mathrm{C}$ can be determined experimentally from $\mathrm{V}_{2} / \mathrm{V}_{1}$ and the phase difference, $\Phi$, of $\mathrm{V}_{2} \mathrm{vs}$. $\mathrm{V}_{1}$ as follows. The experimental quantities are:

$$
\mathrm{x}=\mathrm{V}_{2} / \mathrm{V}_{1}, \quad \mathrm{y}=\tan (\Phi)
$$

Application of AC theory with some algebraic simplification yields

$$
\mathrm{x}=\left(\mathrm{D}^{2}+\omega^{2} \mathrm{C}^{2} \mathrm{R}_{1}{ }^{2}\right)^{1 / 2} /\left\{\mathrm{m}^{2}+\left(\mathrm{m} . \omega \mathrm{CR}+\omega \mathrm{CR}_{1}\right)^{2}\right\}
$$

$$
\mathrm{y}=-\left(\omega \mathrm{CR}_{1}\right) / \mathrm{D}
$$

where $m=1+\left(R_{1} / R_{m}\right)$ and $D=\left\{m .\left(1+\omega^{2} C^{2} R^{2}\right)+\omega^{2} C^{2} R_{1} R\right\}$. $\mathrm{C}$ and $\mathrm{R}$ are related by:

$$
\omega \mathrm{C}=\mathrm{A} /\left(\mathrm{mR}+\mathrm{R}_{1}\right)
$$

where $A=\left\{\left(1+y^{2}\right) / x^{2} y^{2}\right\}^{1 / 2}+(m / y)$. Substitution of (7) in (6) yields a quadratic equation whose non-redundant solution, after algebraic reduction, is:

$$
\mathrm{R}=\mathrm{B} \cdot \mathrm{R}_{1} / \mathrm{A} \cdot \mathrm{y}, \quad \text { where } \mathrm{B}=[1+(\mathrm{y} \cdot \mathrm{m} / \mathrm{A})] /\left[1+(\mathrm{m} / \mathrm{A})^{2}\right]
$$

Substitution of $\mathrm{R}$ in (7) then allows $\mathrm{C}$ to be determined:

$$
\mathrm{C}=\left(\mathrm{A} / \omega \mathrm{R}_{1}\right) \cdot 1 /[1-(\mathrm{m} \cdot \mathrm{B} / \mathrm{A} \cdot \mathrm{y})]
$$

\section{(a) Resistance vs. Voltage at $50-800 \mathrm{~Hz}$. (Series resistance-capacitance model)}

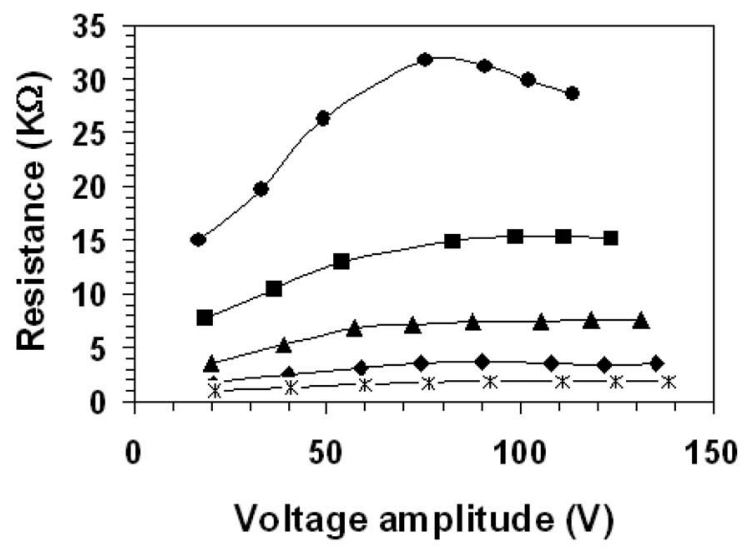

\section{(b) Capacitance vs. Voltage at $50-800 \mathrm{~Hz}$ (Series resistance-capacitance model)}

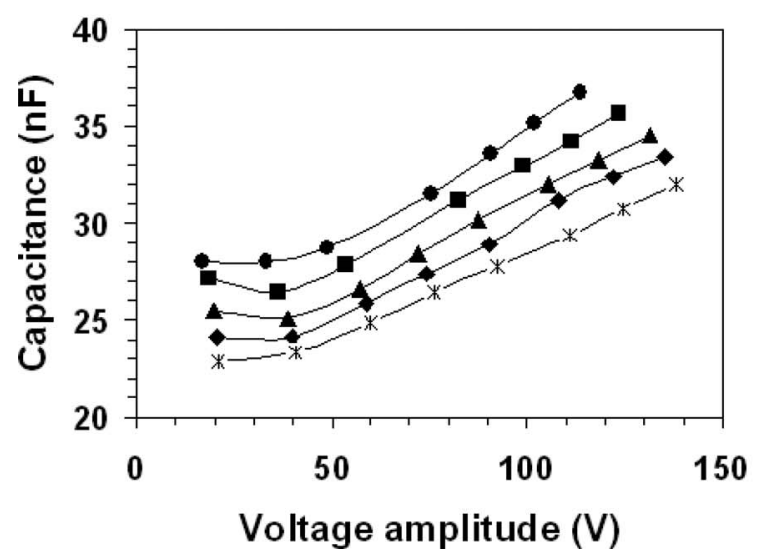

Figure 7. Variation of (a) the effective resistance R, and (b) effective capacitance $\mathrm{C}$ for a single layer ACPEL lamp (30 $\mu$ thickness, $48.75 \mathrm{~cm}^{2}$ area) as a function of sinusoidal AC voltage amplitude at $50 \mathrm{~Hz}(\bullet) 100 \mathrm{~Hz}(\boldsymbol{\square}), 200 \mathrm{~Hz}$ $(\boldsymbol{\Lambda}), 400 \mathrm{~Hz}(\downarrow)$ and $800 \mathrm{~Hz}(*)$ using the analysis for the series configuration resistance - capacitance model.

\section{Results and Discussion}

The experimental quantities, $\left(V_{2} / V_{1}\right)$ and $\Phi$ obtained from the arrangement in Figure 2 can be used to provide independent solutions of the $\mathrm{R}$ and $\mathrm{C}$ defined in Figure 6, as functions of voltage amplitude and frequency. Figures $7 \mathrm{a}$ and $7 \mathrm{~b}$ show the results of this analysis for a single layer ACPEL lamp. The results demonstrate that a practical series resistance - capacitance equivalent circuit is appropriate to describe the single layer ACPEL lamp in operation. Previously proposed equivalent circuits have used three or more crucial elements, ${ }^{19,20}$ which could not be independently examined.

As a first approximation, it is assumed that the dielectric binder will be mainly responsible in determining the capacitative element with some contribution from the phosphor and ferroelectric particles present, whilst the series resistive element will arise solely from the particles which can act as semiconductors. For these components, the effective resistance will be governed by a combination of the external field and the opposing internal field arising from polarization within the particles.

Figure 7 a shows a family of resistance-voltage curves at different frequencies. The resistance-voltage profiles decrease with frequency over the range, and may be approximately explained by the 
frequency dependent term in eqn. 6 in a regime $\mathrm{W}_{\mathrm{p}} \sim 0.5$ at $50 \mathrm{~Hz}$ with $\left(1 / 1+\mathrm{W}_{\mathrm{P}}^{2}\right)=0.8,0.5,0.2,0.060 .02$ at $50,100,200,400$ and $800 \mathrm{~Hz}$, respectively. The highest resistance occurs for the lowest frequency $(50 \mathrm{~Hz})$, with a maximum in the middle of the $\mathrm{AC}$ voltage range studied.

At any given frequency, the capacitance increases nearly linearly beyond a threshold of ca. $50 \mathrm{~V}$. The capacitance-voltage profile monotonically decreases over the $50-800 \mathrm{~Hz}$ range by ca. $20 \%$ overall - and this may be approximately explained also by the frequency-dependent term $\mathrm{W}_{\mathrm{P}}$ in eqn. 2 . in the regime $\mathrm{W}_{\mathrm{P}} \sim 0.5$ at $50 \mathrm{~Hz}\left(\mathrm{~W}_{\mathrm{P}}^{2} / 1+\mathrm{W}_{\mathrm{P}}^{2}\right.$ $=0.2,0.5,0.8,0.94,0.99$ at 50,100,200, 400 and $800 \mathrm{~Hz}$, respectively.) and the requirement that $\mathrm{C}_{\mathrm{P}} \sim 3.5 \mathrm{C}_{\mathrm{D}}$. This implies that the capacitance mainly associated with the phosphor $C_{P}$ is significantly larger than $C_{D}$.

Unactivated $\mathrm{ZnS}$ is a wide band-gap semiconductor (work function: ca. $5.3 \mathrm{eV},{ }^{22}$ bandgap: ca. $\left.3.7 \mathrm{eV}\right) .^{22}$ So far, the binder has been considered as an insulating dielectric. However, it usually contains a ferroelectic material like $\mathrm{BaTiO}_{3}$ to increase the dielectric constant of the binding composition. This should also be considered as an undoped wide band-gap semiconducting material (work function: ca. $4.0 \mathrm{eV},{ }^{23}$ bandgap: ca. $\left.3.2 \mathrm{eV}\right){ }^{24}$ To assess the individual roles of the binder and other main components more closely, some different device structures have been examined at a single frequency $(200 \mathrm{~Hz})$. These were the single layer lamp comprising phosphor $+\mathrm{BaTiO}_{3}$ + binder\}, an identical structure where the phosphor has been replaced by an identical vol/vol proportion of unactivated $\mathrm{ZnS}$, a $\left\{\mathrm{BaTiO}_{3}\right.$ + binder $\}$ composition only, and a binder layer only without other added materials. The results are normalized to a thickness of $30 \mu$ and a device area of $40 \mathrm{~cm}^{2}$, and are presented in Figure 8.

In contrast to the other devices, the "binder only" device can only be analyzed as a resistance and capacitance in parallel, where the resistance measured is in excess of $10 \mathrm{M} \Omega$ at all voltages. Figure $8 \mathrm{~b}$ shows that at a laydown comparable with that of a lamp, the capacitance $(1-2 \mathrm{nF})$ is relatively small. The $\left\{\mathrm{BaTiO}_{3}+\right.$ binder, $1: 4 \mathrm{v} / \mathrm{v}\}$ composition increases the capacitance to $8-9 \mathrm{nF}$, and within experimental error has a flat profile across the voltage range. The corresponding series resistance varies slightly across the voltage range with a shallow minimum of ca. $1 \mathrm{~K} \Omega$ at ca. $40 \mathrm{~V}$.

The normal lamp structure has a capacitance of $21 \mathrm{nF}$ which linearly increases beyond a threshold of ca. $20 \mathrm{~V}$ to $30 \mathrm{nF}$ at ca. $150 \mathrm{~V}$. The corresponding resistance increases linearly from $4 \mathrm{~K} \Omega$ at ca. $20 \mathrm{~V}$ to $8 \mathrm{~K} \Omega$ at $100 \mathrm{~V}$, and remains flat beyond this point. In complete contrast, the lamp structure with unactivated $\mathrm{ZnS}$ exhibits quite different series $\mathrm{C}, \mathrm{R}$ characteristics. The capacitance has a flat profile of ca. $6 \mathrm{nF}$ with respect to voltage, whilst the series resistance profile is markedly lower at all voltages in the range $1-2 \mathrm{~K} \Omega$. Its profile tends to parallel that of the $\left\{\mathrm{BaTiO}_{3}+\right.$ binder $\}$, but at a slightly lower level.

The comparison: $\left\{\mathrm{BaTiO}_{3}+\right.$ binder $\}$ vs. the normal lamp structure can be rationalized when one considers each semiconducting particle to provide an elemental resistance and capacitance in parallel. Small particles of $\mathrm{BaTiO}_{3}$ of ca. $1 \mu$ diameter dispersed throughout the binder will provide an aggregation of many parallel and serial pathways whose resultant resistance and capacitance will be that experimentally observed. In the normal lamp, $3 / 8$ of the volume of the $\left\{\mathrm{BaTiO}_{3}+\right.$ binder $\}$ is replaced by the much larger (ca. $25 \mu$ diameter) phosphor particles. The binder on its own acts as a well-behaved insulating dielectric; its capacitance is essentially constant over the voltage range studied, and exhibits a parallel resistance in excess of $10 \mathrm{M} \Omega$. Incorporation of the $\mathrm{BaTiO}_{3}$ ferroelectric component increases this capacitance, which also remains constant over the voltage range studied. The series resistance, however, initially decreases slightly with increasing voltage $(20-70 \mathrm{~V})$, but then increases at higher voltages $(70-150 \mathrm{~V})$ by about $50 \%$ over this range. By comparison, replacing part of this composition by activated phosphor in a $30 \mu$ coating to form the single layer lamp structure brings more significant changes in the series resistance and capacitance behavior as a function of voltage amplitude, as shown in Figure 8a and 8b. Firstly, the capacitance increases linearly from $20 \mathrm{nF}$ at $30 \mathrm{~V}$ to $30 \mathrm{nF}$ at $150 \mathrm{~V}$. More surprisingly, the series resistance increases linearly from $4 \mathrm{~K} \Omega$ at $20 \mathrm{~V}$ (a) Series Resistance at $200 \mathrm{~Hz}$. $\left(30_{\mu}\right.$ thickness and 40 sq. cm. area)

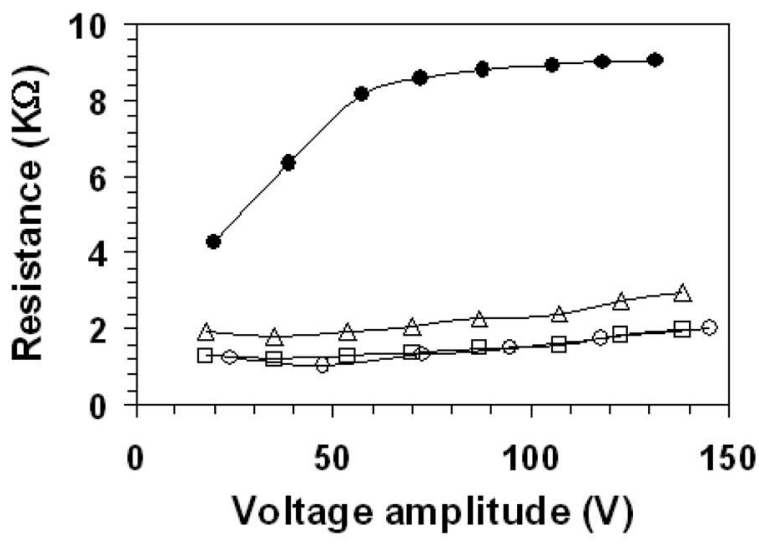

(b) Series Capacitance at $200 \mathrm{~Hz}$.
$\left(30_{\mu}\right.$ thickness, 40 sq.cm. area)

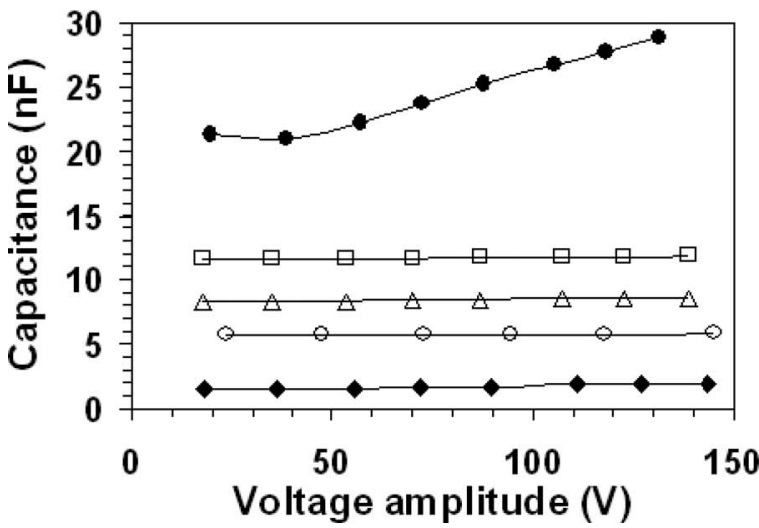

Figure 8. Experimentally determined (a) resistance and (b) capacitance at $200 \mathrm{~Hz}$ of different single layer device structures: $\{\mathrm{Ph}+\mathrm{FE}+$ binder $\}(\bullet)$, \{unactivated $\mathrm{ZnS}+\mathrm{FE}+$ binder $\}(\mathrm{o}),\{\mathrm{FE}+$ binder. 3:7 v/v $\}(\square),\{\mathrm{FE}$ + binder. $1: 4 \mathrm{v} / \mathrm{v}\}(\Delta))$, and $\{$ binder only $\}(\diamond)$. The values for each structure have been normalized to a device area of $40 \mathrm{~cm}^{2}$ and $30 \mu$ thickness. The binder on its own is purely capacitative; when determined as a parallel resistancecapacitance configuration, the resistance is greater than $10 \mathrm{M} \Omega$ at all voltages.

to $8 \mathrm{~K} \Omega$ at $50 \mathrm{~V}$, where the resistance begins to level off. A similar profile behavior is observed at $100-800 \mathrm{~Hz}$ (see Fig. 7a), whilst at $50 \mathrm{~Hz}$ a drop in resistance is observed at voltages greater than $70 \mathrm{~V}$.

The resistive element in the single layer lamp arises mainly from the phosphor component, as the coarse comparison in Fig. 8a shows. The active $\mathrm{ZnS}$ phosphor is a wide band-gap semiconductor doped with $\mathrm{Cu}, \mathrm{Cl}$ (ca. $0.06 \%$ ), and effectively placed between insulating electrodes. The external field across the $25 \mu$ phosphor allows the promotion of electrons to the conduction band, leaving relatively static $\mathrm{Cu}$-located holes. According to MacDonald's analysis, ${ }^{19}$ the ohmic conductivity comprises two contributions in series. One is the normal conductivity of a slab of material between two conducting electrodes, and the second is related to relative time for recombination to occur in the blocked electrode case. This conductivity becomes larger relative to that for normal conductivity if the recombination time relative to the normal dielectric relaxation time becomes shorter. (This would also be consistent with the overall frequency dependence (see Fig. 7a), where the conduction band electrons are swept across the static hole locations following field reversal in each cycle.) At a constant frequency (see Fig. 8a), the resistance increases linearly (i.e. conductivity decreases) with voltage, implying that average charge separation within the cycle 


\section{Energy dissipated per second}

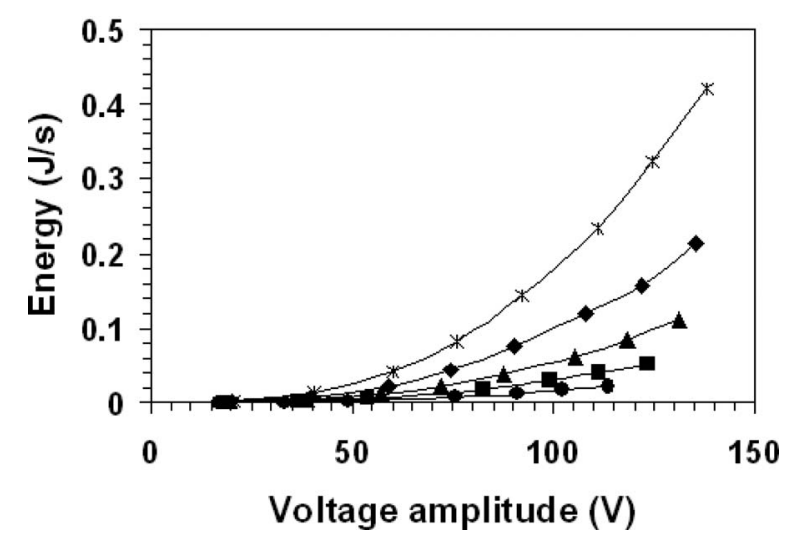

Figure 9. Energy dissipated in a single layer ACPEL lamp (30 $\mu$ thickness, $48.75 \mathrm{~cm}^{2}$ area) for an applied sinusoidal voltage at $50 \mathrm{~Hz}(\bullet) 100 \mathrm{~Hz}(\bullet), 200$ $\mathrm{Hz}(\boldsymbol{\Delta}), 400 \mathrm{~Hz}(\bullet)$ and $800 \mathrm{~Hz}(*)$, calculated from the data in Figure 7.

is greater and the time to recombine is longer. Ultimately a point is reached - possibly limited by the dimension of the particle - where the average recombination time becomes nearly constant. Interestingly, in our example, this also seems to coincide with the onset of significant electroluminescence.

Using the experimental values obtained from the series resistance - capacitance model, the energy dissipated per second may be calculated as a function of voltage and frequency for a sinusoidal waveform. At a given operating voltage in the range 50-100 V, the energy dissipated is approximately proportional to frequency, consistent with eqn. 3 in a regime where $\mathrm{W}^{2} \leq 1$ and an effective series resistance which is inversely proportional to the frequency. Broadly speaking, for our single layer ACPEL lamps under these conditions, light output is nearly proportional to frequency, indicating that when voltages with sinusoidal waveforms are applied, efficacy might only be weakly dependent on frequency. However, at a given frequency, and after the typical threshold at lower voltages $(\leq 40 \mathrm{~V})$, light output seems linearly proportional to the applied voltage. Taken together with the non-linear dependence of energy dissipation on applied voltage in Figure 9, efficacy will tend to optimize at lower voltages.

\section{Conclusions}

The results demonstrate that a practical series resistance - capacitance equivalent circuit can be used to describe the single layer ACPEL lamp in operation provided one accepts that both these elements will be frequency and voltage dependent. Previously proposed equivalent circuits have used three or more crucial elements, ${ }^{19,20}$ which could not be independently examined.

The crucial resistive and capacitive components of this practical equivalent circuit have been independently determined as functions of AC voltage and frequency for a single layer ACPEL device. The physical picture that emerges is that the dielectric \{binder + ferroelectric $\}$ will be mainly responsible for determining the capacitive element since it acts in series with a larger capacitative contribution from the phosphor and ferroelectric particles, whilst the series resistive element will be determined by mainly the phosphor particles, with a minor contribution from the ferroelectric component. The phosphor is semiconducting, and the remarkable changes in the effective series resistance and capacitance of the lamp structure are brought about by the activation of the $\mathrm{ZnS}$. The effective resistance is consistent with a model ${ }^{19}$ where a conventional DC conductivity component is in series with a component governed by the average charge recombination time under the given internal field and frequency conditions. (Here, the internal field is the external field offset by an opposing component arising from mainly from polarization within the particles.)

Using the effective resistance and capacitance values of our equivalent circuit, the average rate of energy dissipation can be easily calculated as a function of applied voltage and frequency. For sinusoidal voltages, first indications are that efficacy will be optimized at low voltages, but will be only weakly dependent on frequency. However, the efficacy of ACPEL devices and particularly its optimisation demands a much more comprehensive assessment than a simple sinusoidal waveform consideration. Electronic relaxation from the resistance-capacitance behavior of the device, as described above, acts together with the relaxation characteristics of the excited states involved in light emission subsequent to any charge recombination step. In practical terms, this means that different waveforms, e.g. sinusoidal, rectangular and triangular, and their respective duty cycles, may have a profound effect at a given frequency and voltage amplitude on the ultimate efficacy achieved. It is beyond the scope of this work to address all these aspects here, but they will be examined fully in a forthcoming report.

\section{Acknowledgments}

We are grateful to the Technology Strategy Board (TSB) (UK) for substantial financial funding in the form of TSB Technology programs for the PLACES, FAB3D, ACTIVEL, SHAPEL, and BEDS programs and to our many industrial collaborators on these programs.

\section{References}

1. G. J. Destriau, Chim. Phys., 33, 587 (1936).

2. G. Destriau and P. Loudette, J. Phys. Radium, 1, 51 (1940).

3. G. Destriau, Phil. Mag., 38, 700 (1947).

4. P. Zalm, G. Diemer, and H. A. Klasens, Philips Res. Rep., 10(3), 205 (1955).

5. G. Destriau, Brit. J. Appl. Phys., 6, S49 (1955).

6. A. G. Fischer, J. Electrochem. Soc., 110, 733 (1963).

7. K. H. Butler and C. W. Jerome, Elec. Eng., 73, 524 (1954).

8. N. E. Grzeskowiak and J. F. Winkel, J. Electrochem Soc., 154, J289 (2007).

9. W. C. Holton, M. R. de Wit, K. Watts, T. L. Estle, and J. Schneider, J. Phys. Chem. Solids, 30, 963 (1969).

10. F. Chen and Y. Xian "Luminescent materials and applications" ed. A. H. Kitai, pp. 249-268, John Wiley \& Sons, Ltd. Chichester (2008).

11. J. Stanley, Y. Jiang, F. Bridges, S. A. Carter, and L. Ruhlen, J. Phys. Condens. Matter, 22, 055301 (2010)

12. C. J. Winscom, R. Withnall, and J. Silver, "Thick Film AC Electroluminescence" Handbook for Display and Information, John Wiley Chichester, 2014 (in print).

13. A. G. Novaled, Press Release. 23 Nov. 2011.

14. G. Williams, "Polymer organic LED lighting." Thorn Lighting presentation, Hardwick Hall U.K., 4 March 2010.

15. S. Tanaka, H. Kobayashi, and N. Miura, "Electroluminescent materials" Phosphor Handbook, 2nd edition, chapter 9(2), pp 709-720, CRC Press, Taylor \& Francis Group, New York (2007).

16. D. J. Park, H. S. Seo, J. T. Ahn, D. K. Oh, W. J. Chung, J. Y. Han, H. S. Jang, and D. Y. Jeon, ETRI Journal, 31, 803 (2009).

17. K. Wani, T. Kanda, and E. Hashimoto, Proceedings of the International Display Workshop (IDW/AD '12, Kyoto, Japan), Vol. 2, p 724 (2012)

18. R. Withnall, J. Silver, P. G. Harris, T. G. Ireland, and P. J. Marsh, J. SID, 19(11), 798 (2011).

19. J. R. MacDonald, Phys. Rev., 92, 4 (1953).

20. K. Sh. Enikeeva, Soviet Physics Journal, 1, 75 (1966).

21. C. J. Winscom, P. G. Harris, and J. Silver, SID Symposium Digest (2014) (in print).

22. Y. Xu and M. A. A. Schoonen, American Mineralogist, 85, 543 (2000).

23. R. H. Tredgold, Space charge conduction in solids, pp.75-79 Elsevier, Amsterdam (1966).

24. K. Suzuki and K. Kijima, Jpn. J. Appl. Phys., 44, 2081 (2005). 